\title{
Investigation of polyamide 11 embrittlement during oxidative degradation
}

\author{
Octavie Okamba-Diogo ${ }^{\text {a, b }}$, Emmanuel Richaud ${ }^{a}$, Jacques Verdu ${ }^{\text {a }}$, François Fernagut ${ }^{\text {b }}$ \\ Jean Guilment ${ }^{\mathrm{b}}$, Bruno Fayolle ${ }^{\mathrm{a},{ }^{*}}$ \\ a Arts et Métiers ParisTech, CNRS, PIMM UMR 8006, 151 bd de l'Hôpital, 75013 Paris, France \\ ${ }^{\mathrm{b}}$ ARKEMA, CERDATO, LEM, Route du Rilsan, 27470 Serquigny, France
}

A R T I C L E I N F O

Article history:

Received 4 August 2015

Received in revised form

5 November 2015

Accepted 10 November 2015

Available online 14 November 2015

Keywords:

Polyamide 11

Embrittlement

Oxidation

\begin{abstract}
A B S T R A C T
Embrittlement processes occurring during thermal oxidation are investigated for stabilized and unstabilized polyamide 11 samples differing by their thicknesses and initial molar masses. Tensile tests were carried out in the temperature range between room temperature and $110{ }^{\circ} \mathrm{C}$ in order to investigate the influence of mechanical testing temperature on the embrittlement coordinates. In the same time, molar mass and crystalline morphology are monitored by size exclusion chromatography (SEC) and DSC/SAXS measurements respectively. The experimental results point out the existence of a critical molar mass for ductile-brittle transition $\mathrm{M}_{\mathrm{c}}^{\prime}$ about $10 \mathrm{~kg} \mathrm{~mol}^{-1}$, independent of sample initial molar mass or stabilization, but depending on tensile testing temperature. However, even if oxidation chain scissions are shown to be clearly responsible for the loss of mechanical properties at failure, the structure-property relationships governing ductile-brittle transition require a mixed criterion involving molar mass and crystalline morphology, especially the interlamellar distance. For this purpose, specific molar mass crystalline morphology relationships are investigated.
\end{abstract}

\section{Introduction}

Thermal oxidation is a critical process responsible for the deterioration of the mechanical and physical properties during polyamide service life. It is well known that PA samples exposed under air are subjected to discoloration (yellowing) [1,2] and embrittlement which is the sudden transition from an initial ductile behavior to a brittle one [3]. Oxidation proceeds by a radical chain reaction that affects the molar mass distribution through mainly chain scissions occurring exclusively in the amorphous phase since the crystalline phase remains tight to oxygen [4-6]. In previous articles, we demonstrated the predominance of random chain scissions over crosslinking events during the homogeneous thermal oxidation of unstabilized PA11 films $[7,8]$. This article investigates PA11 structure-property relationships, especially between molar mass changes induced by chain scissions and mechanical properties.

The relationships between molar mass and mechanical behavior

\footnotetext{
* Corresponding author.

E-mail address: bruno.fayolle@ensam.eu (B. Fayolle).
}

have been already proposed in the literature for amorphous polymers [8]. The ductile-brittle transition occurs in a sharp molecular weight interval so that a critical molar mass $\left(\mathrm{M}_{\mathrm{c}}{ }_{\mathrm{c}}\right)$ can be defined [3]: if $\mathrm{M}_{\mathrm{n}}>\mathrm{M}_{\mathrm{c}}^{\prime}$ then the sample displays a ductile behavior. This critical molar mass is often associated to molar mass between entanglements $\left(\mathrm{M}_{\mathrm{e}}\right)$. Indeed, entanglement network is considered as active mechanically speaking provided that the molar mass has a value significantly higher than $\mathrm{M}_{\mathrm{e}}$. More precisely, it has been proposed that $\mathrm{M}_{C}^{\prime}$ order of magnitude is close to five times the molar mass between entanglement i.e. $\mathrm{M}^{\prime}{ }_{\mathrm{C}} \sim 5 \mathrm{M}_{\mathrm{e}}[9,10]$.

The case for semi-crystalline polymers appears to be more complicated since crystalline morphology can affect the molar mass-mechanical behavior relationship. The ductile behavior for semi-crystalline polymers is generally attributed to the presence of tie-molecules allowing a sufficient interlamellar connectivity for plastic deformation [11]. Concerning the semi-crystalline polymers having an amorphous phase in rubbery state, it has been proposed that the ductile-brittle transition is reached when amorphous layer thickness $\left(l_{a}\right)$ becomes lower than a critical value $\left(l_{a c}\right)$. Since the amorphous layer thickness depends on molar mass according to the following scaling law $l_{\mathrm{a}} \sim \mathrm{M}_{\mathrm{W}}^{1 / 2}$ [12], $\mathrm{l}_{\mathrm{aC}}$ is expected to correspond to a critical molar mass value $\mathrm{M}_{\mathrm{wc}}$. In the case of semi-crystalline 
chemical degradation, chain scissions are responsible for molar mass decay but also for crystallinity increase. This latter phenomenon, often called chemi-crystallization, is due to the fact that the chain fragments liberated by chain scissions in the amorphous region can integrate the crystalline phase by a lamellar thickening process [13-16]. That is the reason why the previous scaling law $\left(l_{\mathrm{a}} \sim \mathrm{MW}_{\mathrm{W}}^{1 / 2}\right)$ can be valid to describe crystalline morphology changes during a random chain scission process.

The present article is aimed at studying PA11 embrittlement process during the homogeneous sample thermal oxidation in order to assess the structure-property relationships, especially the critical molar mass value governing the ductile-brittle transition. Several PA11 samples differing by their initial molar mass, their stabilizer content or their thickness will be compared so as to conclude on the intrinsic behavior of $\mathrm{M}^{\prime} \mathrm{C}$.

The second objective of this study is to investigate influence of tensile testing temperature on the ductile-brittle transition induced by oxidation. Since the PA11 glass transition temperature $T_{g}$ is close to $50{ }^{\circ} \mathrm{C}$, we have chosen to follow the embrittlement process at several testing temperatures below and above $T_{g}$ up to $110{ }^{\circ} \mathrm{C}$ in order to determine the eventual influence of the physical state of the amorphous phase on the embrittlement characteristics.

\section{Experimental}

The samples are listed in Table 1 with their designation and initial microstructural, macromolecular and mechanical properties. Unstabilized PA11 samples were prepared as described in our previous articles [7]. Four PA11 grades differing from the polycondensation condition (the catalyzer and its concentration) were investigated and PA11 V corresponds to our standard grade. The main difference between the grades is the melt viscosity linked to the molar mass $\left(M_{n 0}, M_{w 0}\right.$ in Table 1). Therefore, besides the unstabilized film, PA11 V grade was used to prepare a 1-mm thick plaque (PA11 V pl) by micro-injection [7] and phenol stabilized film (PA11 V 3).

The residual phenol concentration was determined by High Performance Liquid Chromatography (HPLC) provided by Agilent Technologies (1100 Series) equipped with a UV detector $(280 \mathrm{~nm})$. The separation was performed through the chromatographic column (5 $\mu \mathrm{m}, \mathrm{L} 125 \mathrm{~mm}, \varnothing 4 \mathrm{~mm}$ and $120 \AA$ ) filled with grafted silica C18 (Hypersil ODS) and the mobile phase was methanol (HPLC grade, $\geq 99.9 \%$ purity provided by SigmaAldrich) at a constant flow rate of $1.0 \mathrm{~mL} \mathrm{~min}^{-1}$. The quantitative identification was made with calibration by Irganox $^{\circledR} 1098$ solutions.

The samples were dried under vacuum overnight at $50{ }^{\circ} \mathrm{C}$ prior to perform the aging at $110{ }^{\circ} \mathrm{C}$ in an air ventilated oven XUO 32 supplied by France Etuves. The homogeneity of oxidation has been confirmed by measuring oxidative species across the thickness of plate samples using FTIR microscopy elsewhere $[7,17]$ and in our case, the technique was widely described in a previous article [18].

Size Exclusion chromatography (SEC) measurements were performed to follow the changes in the average molar mass $M_{n}$ and $M_{w}$ during oxidation. The conditions for SEC measurements have been described elsewhere [7].

The changes in crystallinity were investigated by DSC analysis performed on TA Instruments Q1000 with temperature ramp of $10{ }^{\circ} \mathrm{C} \mathrm{min}-1$ from 50 to $250{ }^{\circ} \mathrm{C}$. The crystallinity ratio $\mathrm{X}_{\mathrm{C}}$ is determined as follows:

$X_{C}=\frac{\Delta H_{f}}{\Delta H_{f}^{\circ}}$

With $\Delta \mathrm{H}_{\mathrm{f}}^{\circ}=226.4 \mathrm{~J} \mathrm{~g}^{-1}$ (PA11 melting enthalpy for an ideally $100 \%$ crystalline sample) [19].

The amorphous layer $l_{\mathrm{a}}$ was determined by performing small angle X-ray scattering (SAXS) patterns at room temperature on aged PA11 V pl samples by means of the diffractometer Genix Xenocs. The apparatus consists of a X-ray source using a copper anode $\mathrm{K} \alpha$ radiation, the wavelength being $1.54 \AA$, a monochromator, a collimator, a specimen chamber and a computer equipped with the MAR300 software. The sample-to-detector distance was $1418 \mathrm{~mm}$. Silver behenate standard reference material was used for sample-to-detector distance calibration. The exposure time was $7800 \mathrm{~s}$. The active area was $20 \times 20 \mathrm{~cm}$ and the scattering intensity $64 \times 64$ array. The 2D patterns were treated using Fit2D software developed by A. Hammersley [20]. The long period ( $\left.L_{P}\right)$ was determined by the azimuthal integration of the 2D pattern from isotropic sample and the intensity profiles were corrected by Lorentz-factor $\mathrm{I}(\mathrm{q})^{2}$; $=\mathrm{f}(\mathrm{q})$ with the Bragg relation [21]:

$L_{P}=\frac{2 \pi}{q_{M A X}}$

Where $\mathrm{q}=4 \pi \sin \theta / \lambda$ and $\mathrm{q}_{\mathrm{MAX}}$ the wave vector corresponding to peak scattering intensity determined from the intensity profile using OriginPro ${ }^{\circledR} 2015$.

The crystal thickness $\mathrm{L}_{\mathrm{c}}$ is given by the following equation:

$L_{C}=L_{P}\left(\frac{\rho}{\rho_{C}}\right) x_{C}$

Where $\rho$ is the PA11 density $\left(1.013 \mathrm{~kg} \mathrm{~L}^{-1}\right)$ and $\rho_{\mathrm{c}}$ the crystalline density $\left(1.130 \mathrm{~kg} \mathrm{~L}^{-1}\right)$ [22].

The glass transition temperature $\left(\mathrm{T}_{\mathrm{g}}\right)$ of unaged PA11 V sample was determined by means of dynamic mechanical thermal analysis tests (DMTA) on the DMA Q800 provided by TA Instruments. The temperature range was between 30 and $170^{\circ} \mathrm{C}$, at a heating rate of $2{ }^{\circ} \mathrm{C} \min ^{-1}$ and at a frequency of $1 \mathrm{~Hz}$, and $\mathrm{T}_{\mathrm{g}}$ was about $60{ }^{\circ} \mathrm{C}$. Hence, three tensile testing temperatures were chosen beside room temperature $\left(25^{\circ} \mathrm{C}\right): 50,80$ and $110{ }^{\circ} \mathrm{C}$ in order to investigate the influence of the state of the amorphous phase during tensile tests.

Tensile tests were carried out on Instron $^{\circledR} 5889$ machine equipped with a thermal chamber that controls the test temperature during the experiment. A $1 \mathrm{kN}$ cell load was used; the crosshead speed was $10 \mathrm{~mm} \mathrm{~min}^{-1}$. For each PA11 grade and exposure time at least 7 dumbells $\left(\mathrm{L}_{0}=20 \mathrm{~mm}\right)$ were tested.

Table 1

Sample designation and initial macromolecular and mechanical properties: * the film thickness was between 60 and $120 \mu \mathrm{m}$ and ${ }^{* *}$ the plates were 1 mm thick

\begin{tabular}{|c|c|c|c|c|c|c|c|}
\hline Sample name & $\mathrm{M}_{\mathrm{n} 0}\left(\mathrm{~kg} \mathrm{~mol}^{-1}\right)$ & $\mathrm{M}_{\mathrm{w} 0}\left(\mathrm{~kg} \mathrm{~mol}^{-1}\right)$ & PI & $\varepsilon_{\mathrm{Ro}}(\%)$ & $\mathrm{X}_{\mathrm{C}}$ & Geometry & {$\left[\operatorname{Irganox}^{\circledR} 1098\right]$ wt \% } \\
\hline PA11 HV & 21.7 & 45.5 & 2.1 & $279-368$ & 0.22 & Film* & - \\
\hline PA11 V & 19.8 & 39.7 & 2 & 304 & 0.20 & Film* & - \\
\hline PA11 HF & 12.5 & 23.8 & 1.9 & 313 & 0.26 & Film* & - \\
\hline PA11 F & 12.6 & 23.8 & 1.9 & 336 & 0.24 & Film* & - \\
\hline PA11 V pl & 13.2 & 42.2 & 3.2 & 437 & 0.22 & Plate** & - \\
\hline PA11 V 3 & 21.3 & 46.8 & 2.2 & 379 & 0.24 & Film* & 0.14 \\
\hline
\end{tabular}




\section{Results}

\subsection{Molar mass and crystallinity modifications}

Since PA11 oxidation leads to a predominant chain scission process, the most pertinent physical parameter to follow degradation is the molar mass characterized here by SEC. The changes in $\mathrm{M}_{\mathrm{n}}$ for unstabilised PA11 films during degradation time are shown in Fig. 1.

First of all, whereas the initial molar mass (Mn0) for PA11 V and PA11 HV is close to $20 \mathrm{~kg} \mathrm{~mol}^{-1}$, the initial molar masses for PA11 HF is close to $12.5 \mathrm{~kg} \mathrm{~mol}^{-1}$. In all cases, a mass molar decrease with a maximum rate at the beginning of the exposure. is witnessed. The molar mass seems to reach a pseudo plateau close to $5 \mathrm{~kg} \mathrm{~mol}^{-1}$ whatever the initial $\mathrm{M}_{\mathrm{n} 0}$ samples. Then, it is possible to overlap all curves by shifting the low initial $\mathrm{M}_{\mathrm{n} 0}$ samples to higher oxidation degree $(\sim 600 \mathrm{~h})$. The numbers $\mathrm{s}$ of chain scissions and $\mathrm{x}$ of crosslinks per mass unit were calculated from Saito's equations [21]:

$n=\frac{1}{M_{n(t)}}-\frac{1}{M_{n 0}} ; \quad w=\frac{1}{M_{w(t)}}-\frac{1}{M_{w 0}}$

In the case of PA11 oxidation, the variation of the polydispersity index (PI) is negligible. Moreover, PI remains around 2, one can write:

$s=\frac{2}{3}(2 n-w)$

$x=\frac{1}{3}(n-2 w)$

The value of $\mathrm{s}$ and $\mathrm{x}$ is compiled in Table 2 for some aged film samples.

The results call for the following comments:

a) Chain scissions predominate largely over crosslinking [7].

b) The initial rate of molar mass decrease is an increasing function of the initial molar mass value as predicted from Saito's equations. As a matter of fact, neglecting crosslinking in a first approximation and deriving Eq. (4) one obtains:

$\left(\frac{d s}{d t}\right)_{0}=-\frac{1}{M_{n 0}^{2}}\left(\frac{d M_{n}}{d t}\right)_{0}$

Supposing that oxidative degradation is a random process, the

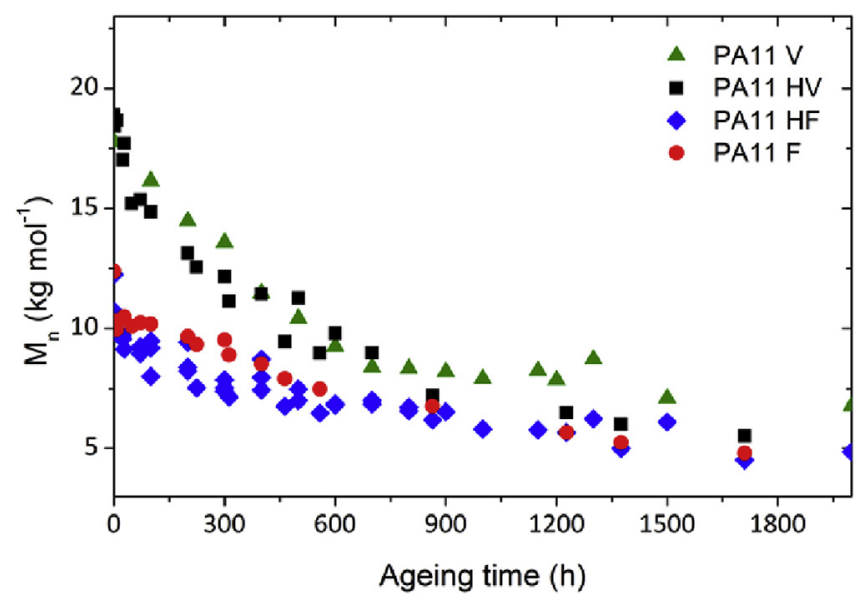

Fig. 1. $\mathrm{M}_{\mathrm{n}}$ changes during air ageing at $110{ }^{\circ} \mathrm{C}$ for unstabilized PA11 film samples. initial rate of chain scission in unstabilized samples is expected to be independent of initial molar mass so that the initial rate of molar mass decrease is effectively expected to increase with $\mathrm{M}_{\mathrm{n} 0}$ :

$$
\left(\frac{d M_{n}}{d t}\right)_{0}=-M_{n 0}^{2}\left(\frac{d s}{d t}\right)_{0}
$$

c) From the calculated values of s, one can estimate the initial rate of chain scission. As expected, it takes a value almost independent of initial molar mass $(d s / d t)_{0} \sim 10^{-8} \mathrm{~mol} \mathrm{~kg}^{-1} \mathrm{~s}^{-1}$.

Fig. 2 shows molar mass changes for stabilized and unstabilized PA11 V film and unstabilized PA11 V plate as function of exposure time, this latter being in log scale to ease the reading. First, the molar mass decrease is similar to unstabilized PA11 V plate and film which indicates that the chain scission rate is not affected by the processing conditions (extrusion vs injection molding) and the sample thickness ( $70 \mu \mathrm{m}$ vs $1 \mathrm{~mm}$ ). In contrast, the kinetic behavior is deeply modified in the presence of stabilizer (Irganox ${ }^{\circledR} 1098$ ). In the short term, there is a small but significant increase of molar mass opposite to the fast decrease observed in unstabilized samples. In the long term, degradation becomes predominant but significantly slowed down relatively to unstabilized samples.

The initial increase of $M_{n}$ can be attributed to slow postpolycondensation process. This phenomenon also exists in unstabilized samples but it is obscured by oxidative degradation, this latter being inhibited by the stabilizer (as long as stabilizer remains in the sample). When the stabilizer has been almost totally consumed, i.e. after approximately $1000 \mathrm{~h}$ at $110{ }^{\circ} \mathrm{C}$, degradation becomes predominant and the curve of stabilized sample rejoins progressively the curve of unstabilized samples (For more information and a comprehensive modelling of these aspects, see Refs. $[7,18])$.

Since polydispersity index remains close to 2 and is not significantly affected by the chain scission process, it seemed to us useless to report polydispersity index and weight average molar mass values. The fact that the polydispersity index is unchanged indicates as well that chain scission can be considered as a random process into the amorphous phase, this point being valid whatever the sample geometry (70 $\mu \mathrm{m}$ or $1 \mathrm{~mm}$ thick) considered here.

As mentioned in introduction, an increase of crystallinity is often associated to semicrystalline polymer oxidation. Hence, crystallinity changes have to be taken into account. Crystallinity ratio values assessed by DSC for unstabilized polyamide 11 films are reported in Fig. 3 as a function of exposure time. For all PA11 under consideration here, crystallinity ratio $\left(\mathrm{X}_{\mathrm{C}}\right)$ appears to be slightly modified by the chain scission process: In the early stage of the exposure corresponding to the first $48 \mathrm{~h}$, a significant increase can be attributed to annealing (knowing same observations are obtained by performing exposition under anaerobic atmosphere up to $100 \mathrm{~h}$ ) whereas the continuous increase observed between 100 and $1200 \mathrm{~h}$ of exposure is undoubtedly associated to a chemicrystallization process: chain scissions in the amorphous phase (in rubbery state) allow to integrate some broken chains into the crystalline phase. It is noteworthy this $\mathrm{X}_{\mathrm{C}}$ increase doesn't lead to a significant modification of the shape of the DSC melting peak indicating that no new lamellae appear-during the chemicrystallization process.

As a result, it is now possible to propose a link between the chain scission process and the chemi-crystallisation by introducing a yield of chemi-crystallisation ( $\mathrm{y}$ ) which can be defined as following: 
Table 2

$\mathrm{s}$ and $\mathrm{x}$ for some aged PA11 films during air aging at $110{ }^{\circ} \mathrm{C}$.

\begin{tabular}{|c|c|c|c|c|c|c|c|c|}
\hline \multirow[t]{2}{*}{ Aging time (h) } & \multicolumn{2}{|l|}{ PA11 HV } & \multicolumn{2}{|l|}{ PA11 V } & \multicolumn{2}{|l|}{ PA11 HF } & \multicolumn{2}{|l|}{ PA11 F } \\
\hline & $\mathrm{s}\left(\mathrm{mol} \mathrm{kg}{ }^{-1}\right)$ & $\mathrm{x}\left(\mathrm{mol} \mathrm{kg}^{-1}\right)$ & $\mathrm{s}\left(\mathrm{mol} \mathrm{kg}{ }^{-1}\right)$ & $\mathrm{x}\left(\mathrm{mol} \mathrm{kg}^{-1}\right)$ & $\mathrm{s}\left(\mathrm{mol} \mathrm{kg}{ }^{-1}\right)$ & $\mathrm{x}\left(\mathrm{mol} \mathrm{kg}^{-1}\right)$ & $\mathrm{s}\left(\mathrm{mol} \mathrm{kg}^{-1}\right)$ & $\mathrm{x}\left(\mathrm{mol} \mathrm{kg}^{-1}\right)$ \\
\hline Unaged & 0 & 0 & 0 & 0 & 0 & 0 & 0 & 0 \\
\hline 100 & 0.01014 & 0.00213 & 0.00465 & $3.29 \mathrm{E}-04$ & 0.01576 & 0.00285 & 0.01113 & 0.00286 \\
\hline 200 & 0.01529 & 0.00285 & 0.01217 & 0.00121 & 0.02095 & 0.00304 & 0.01437 & 0.00357 \\
\hline 300 & 0.01826 & 0.00273 & 0.01438 & 0.00122 & 0.02503 & 0.00334 & 0.0158 & 0.00426 \\
\hline 400 & 0.02178 & 0.00311 & 0.02238 & 0.00282 & 0.02495 & 0.00398 & 0.02304 & 0.00564 \\
\hline
\end{tabular}

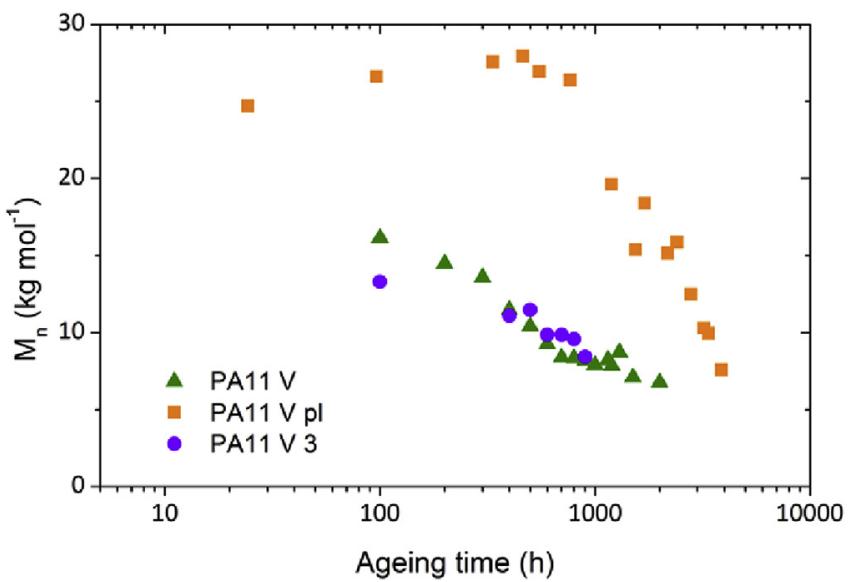

Fig. 2. $M_{n}$ changes during air ageing at $110{ }^{\circ} \mathrm{C}$ for the stabilized film PA11 V 3 compared to PA11 V film (70 $\mu \mathrm{m}$ thick) and PA11 V plate $(1 \mathrm{~mm})$.

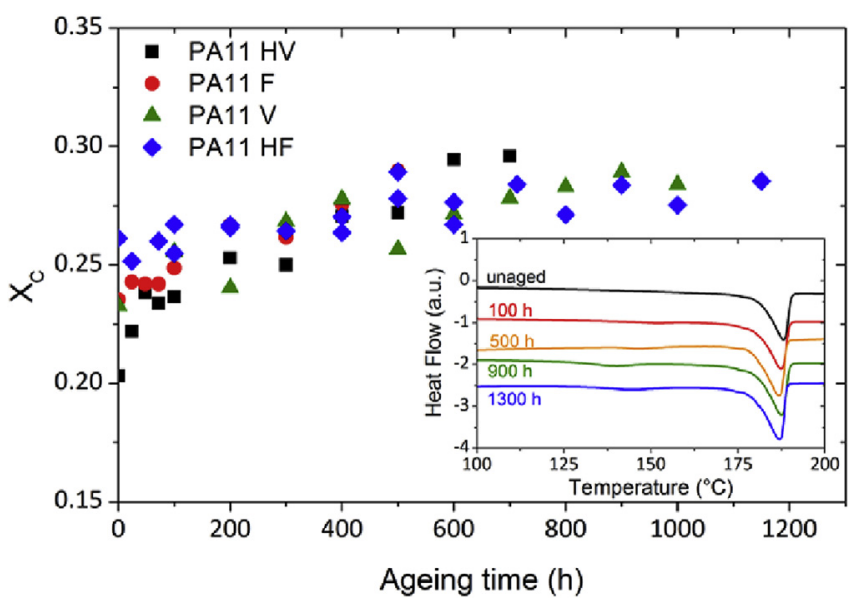

Fig. 3. Some thermograms for PA11 V during air ageing at $110{ }^{\circ} \mathrm{C}$ and the changes of crystallinity ratio for unstabilized polyamide 11 films.

$y=\frac{1}{M_{m}} \cdot \frac{d X_{C}}{d s}$

with $\mathrm{M}_{\mathrm{m}}$ being the PA11 monomer molar mass.

To assess $\mathrm{y}$, crystallinity ratio is plotted against chain scission number in Fig. 4. According to Fig. 4, crystallinity ratio increases quasi linearly with the number of chain scissions and the slope corresponds to a chemi-crystallization yield y $\sim 4$ monomer units per chain scission.

From SAXS and DSC measurements, amorphous layer thickness $\left(l_{a}\right)$ can be determined. According to Rault [12], $l_{a}$ is linked to molar mass through a following scaling law which can be expressed in a first approach by: $l_{a} \propto M_{w}^{2}$. In order to check the validity of this

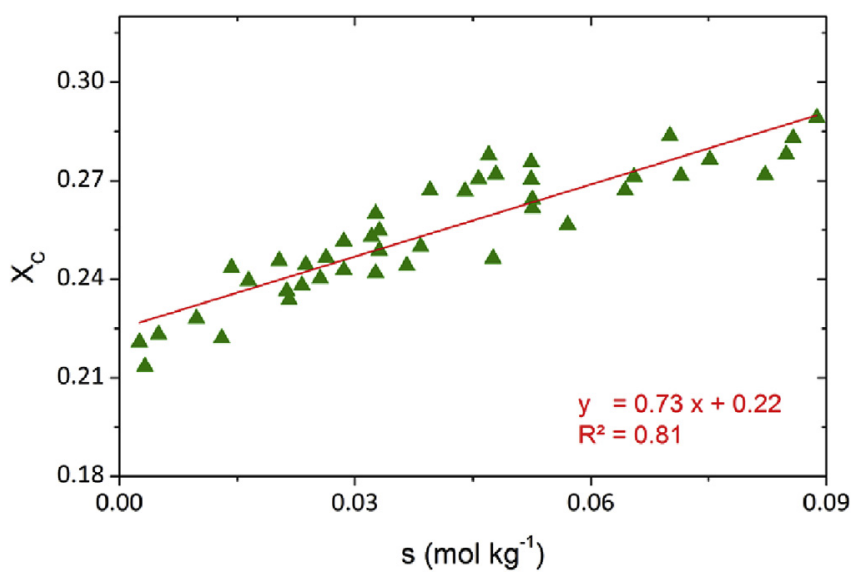

Fig. 4. Crystallinity ratio as a function of chain scission number for unstabilized polyamide 11 films during air ageing at $110{ }^{\circ} \mathrm{C}$.

scaling law in our case, Fig. 5 shows amorphous layer thickness as a function of square root of molar mass $\mathrm{M}_{\mathrm{w}}$. A reasonable agreement is obtained on both average molar mass, which confirms this approach.

\subsection{Tensile behavior changes at room temperature}

Since ductile-brittle transition is expected to occur during degradation, we propose here to witness this transition by following mechanical behavior in tensile mode. Even if this mode is not fully appropriate to monitor failure properties, it is largely used to study mechanical properties in literature [3]. Starting from this point, tensile tests at room temperature $\left(25^{\circ} \mathrm{C}\right)$ have been

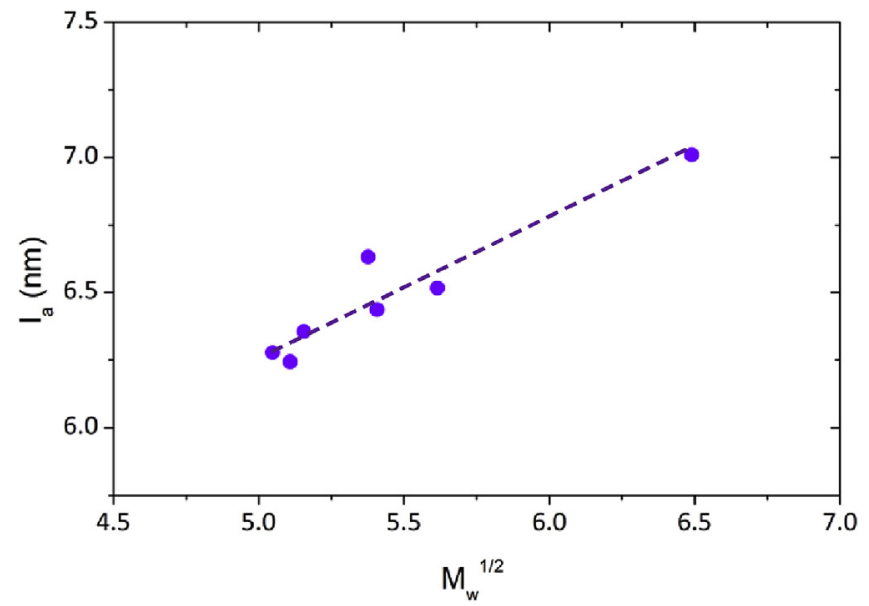

Fig. 5. Amorphous layer thickness as a function of molar mass for unstabilized polyamide 11 plate during air ageing at $110{ }^{\circ} \mathrm{C}$. 
performed on samples having different degradation states. Fig. 6 reports engineering stress-strain curves for unstabilized PA11 V at several times of exposure.

First, stress-strain curves shape around the yield point is slightly modified by annealing during the early period of exposure as it has been already seen with the crystallinity ratio measurements by DSC. In order to dissociate annealing and chain scission process, stress-strain curve for annealed PA11 V under $\mathrm{N}_{2}$ and the asreceived sample were inserted as well. As a result, annealing process modifies plasticity behavior (especially increase of yield stress) but do not affect strain at break. By increasing duration (time exposure in air), it is witnessed that strain at break decreases although the stress-strain curve shape is not affected by the chain scission process. In other words, chain scission leads only to reduce plastic deformation until the failure. As a result, only strain at break parameter appears as pertinent to characterize the embrittlement process. That is the reason why only strain at break values is reported to put in evidence the ductile-brittle transition in Fig. 7 (each point is the average of 7 tests). In this Figure, normalized strain at break is plotted as a function of time for all polymers under study. Our data were normalized by dividing strain at break by the initial strain at break for each PA11 sample $\left(\varepsilon_{\mathrm{R}} / \varepsilon_{\mathrm{R} 0}\right)$. Arbitrarily, time to embrittlement $\left(t_{\mathrm{F}}\right)$ is defined as the time when normalized strain at break reaches $50 \%$ of its initial value.

These results can be summarized as follows:

First for all the samples one can observe a sudden change from a ductile plateau where $\varepsilon_{\mathrm{r}} / \varepsilon_{\mathrm{r} 0} \geq 1$ to a pseudo brittle plateau where $\varepsilon_{\mathrm{r}} /$ $\varepsilon_{\mathrm{r} 0} \leq 0.25$. This behavior clearly suggests the existence of a critical structural state and justifies the use of the terms "ductile-brittle transition" and "embrittlement".

Second the time to embrittlement at $110^{\circ} \mathrm{C}$ in air is about $100 \mathrm{~h}$ for the unstabilized low molar mass samples, $400 \mathrm{~h}$ for the unstabilized samples whatever their thickness (70 $\mu \mathrm{m}$ or $1 \mathrm{~mm}$ ) and about $1600 \mathrm{~h}$ for the stabilized sample. The time to embrittlement appears to vary in the same way as the number of chain scissions with molar mass, sample thickness and stabilization.

Third a slight increase of the strain at break is observed at the beginning of exposure. Here also it is tempting to explain this phenomenon by the increase of molar mass due to postpolycondensation.

\subsection{Effect of tensile testing temperature}

The above reported experiment was repeated but at different

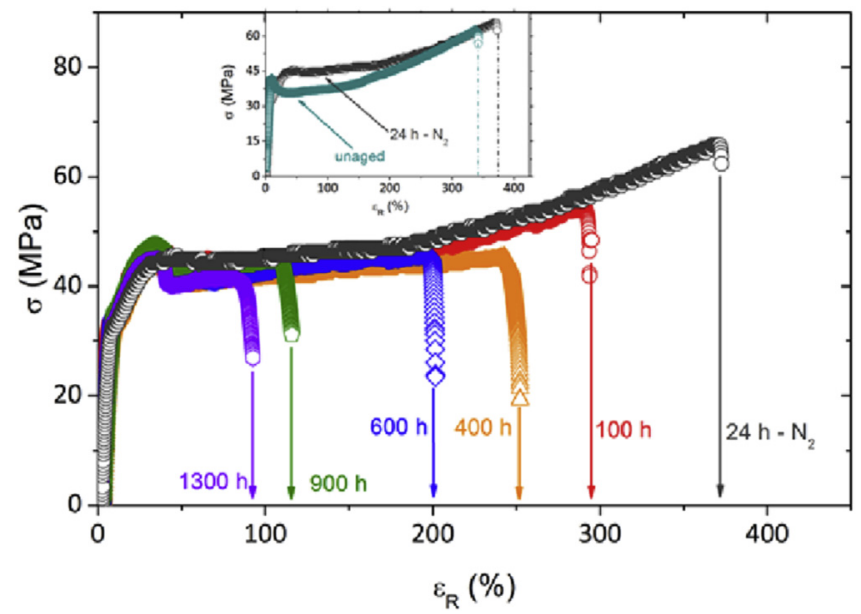

Fig. 6. Stress-strain curves for PA11 V during air ageing at $110{ }^{\circ} \mathrm{C}$ (mechanical tests performed at room temperature).

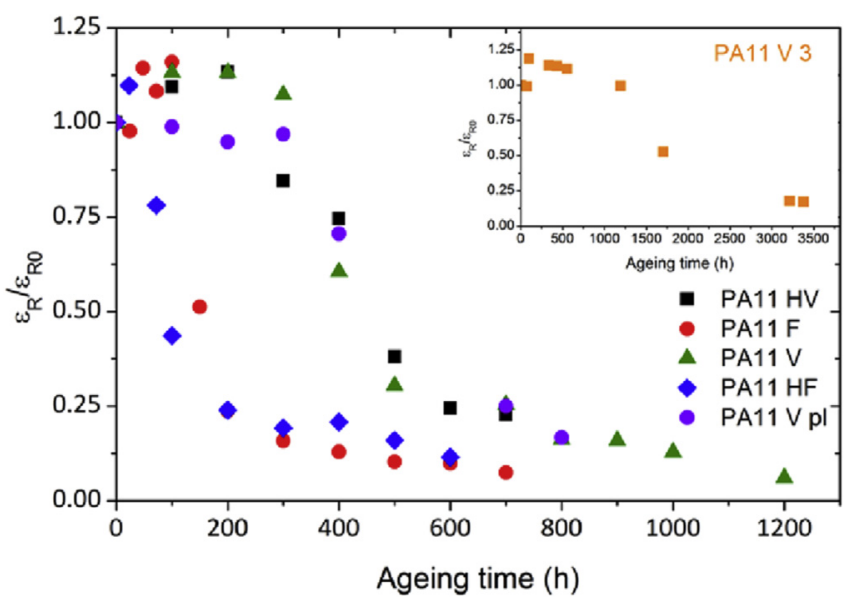

Fig. 7. Normalized $\varepsilon_{\mathrm{R}}\left(\varepsilon_{\mathrm{R}} / \varepsilon_{\mathrm{R} 0}\right)$ changes during air ageing at $110{ }^{\circ} \mathrm{C}$ for all samples.

temperatures for tensile testing $\left(50,80\right.$ and $\left.110^{\circ} \mathrm{C}\right)$. The objective is to follow the ductile-brittle transition on both sides of the glass transition temperature. For this purpose, strain-stress curves for each testing temperatures for the annealed PA11 are shown in Fig. 8. This figure calls for the following comments:

First, as expected, the yield stress decreases almost linearly with temperature (Fig. 9). In the temperature interval under study, the slope is: $\Delta \sigma_{y} / \Delta T \sim-0.36 \mathrm{MPa}^{-1}$. Extrapolating this straightline, one would find that the yield vanishes at about $140{ }^{\circ} \mathrm{C}$. The yield characteristics are almost independent of the degradation state.

Second, the maximum strain at break is significantly higher on the rubbery side $(\geq 350 \%)$ than on glassy side ( $\leq 275 \%$ ). Indeed, $\varepsilon_{\mathrm{r}}$ is sharply linked to the degradation state.

Third, the rupture envelope remains close to the initial stressstrain curve (Fig. 8), showing that the structural changes induced by thermal ageing affect almost exclusively the fracture process but do not affect the rest of the mechanical behavior.

Fourth, the results show that a sample declared brittle from testing at $25^{\circ} \mathrm{C}$ remains ductile at $110^{\circ} \mathrm{C}$ In other words, for a given oxidized state, an increase of testing temperature delays the ductile-brittle transition induced by oxidation. This behavior has been also observed by Zhang et al. in the case of irradiated polypropylene samples: The ductile-brittle temperature rises as the irradiation dose increases, i.e. molar mass decreases [23].

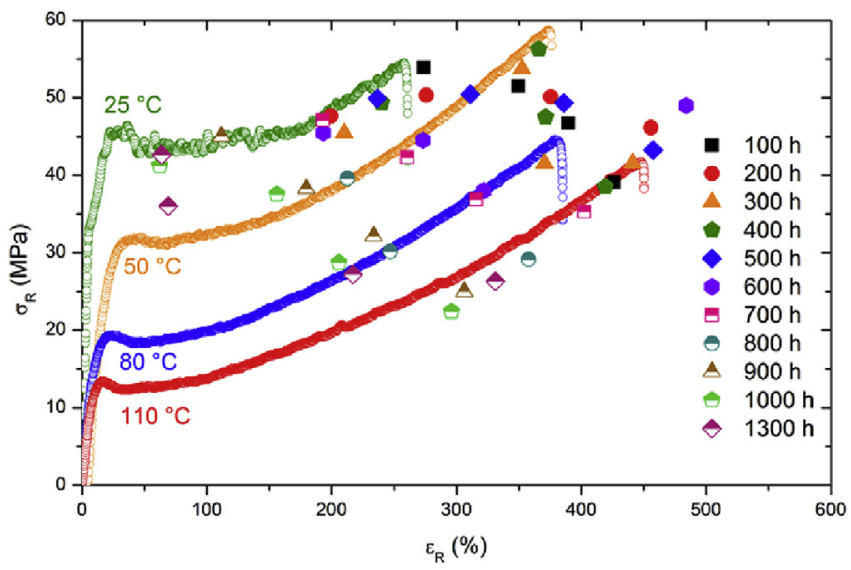

Fig. 8. Stress-strain curves as a function of tensile testing temperature and stress-strain values at failure as a function of degradation time. 


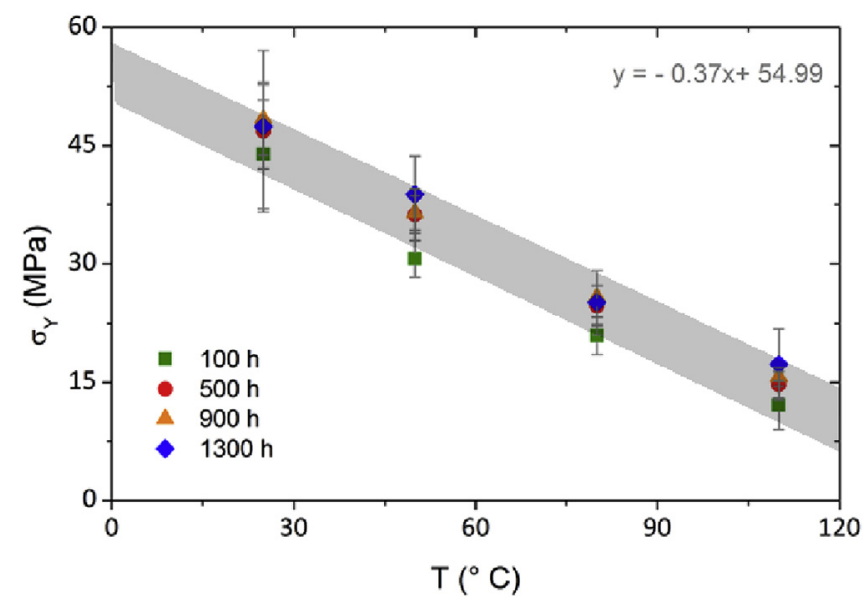

Fig. 9. Influence of tensile test temperature on $\sigma_{\mathrm{Y}}$ as a function of degradation time.

\section{Discussion}

\section{1. $M^{\prime}{ }_{C}$ assessment}

It has been shown above that the major consequence of PA11 thermal oxidation is random chain scission. An important consequence of this molar mass decrease is a crystalline lamella thickening and thus a decrease of the interlamellar distance $l_{\mathrm{a}}$. This latter change can be linked to the number of chain scissions through the concept of chemi-crystallization yield $y$. The problem now is first to identify the real cause of embrittlement: decrease of the entanglement density in the amorphous phase? Loss of tie molecules or change in micromechanical stress state linked to the decrease of the interlamellar distance? All these hypotheses have been evoked in the literature but they lacked of quantitative validation. The question now is to establish a link between an oxidation state and this ductile-brittle transition.

According to the simplest hypothesis, the ductile-brittle transition would correspond to a critical value of molar mass. This is the reason why the strain at break at $25{ }^{\circ} \mathrm{C}$ was plotted against molar mass for all the unstabilized samples under study, in Fig. 10.

In a first approach it could be concluded from this figure that the ductile-brittle transition occurs at a critical molar mass almost independent of the sample structure or geometry:

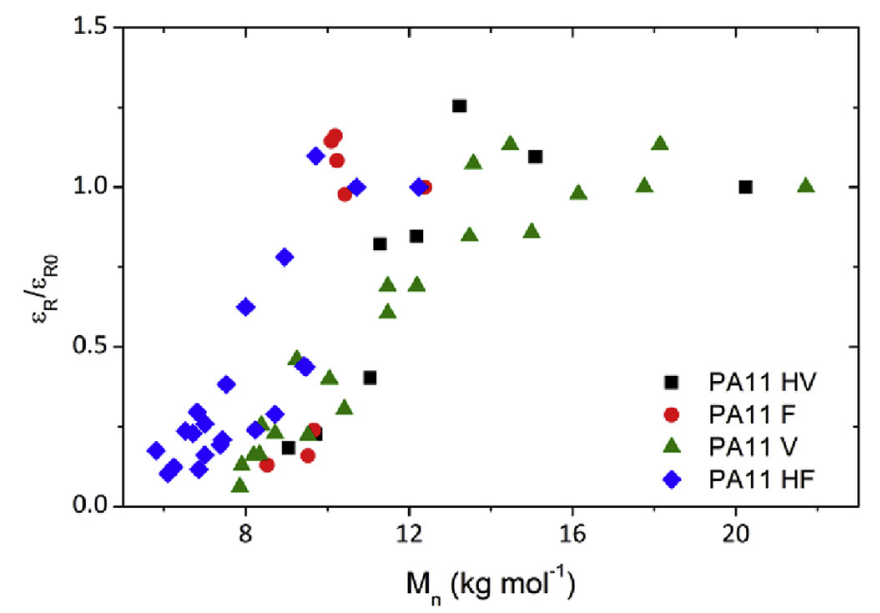

Fig. 10. Normalized strain at failure (@RT) as a function of molar mass $\left(M_{n}\right)$ for unstabilised PA11 films having various initial molar mass.
$\mathrm{M}_{\mathrm{C}}^{\prime}=10 \pm 1 \mathrm{~kg} \mathrm{~mol}^{-1}$. However, a small shift towards low molar mass values can be observed for the low molar mass sample PA11 HF and perhaps also PA11 F. Is this shift significant? It seems interesting to search for a more universal criterion.

For a given polymer base (PA11 V), there is no clear difference between films and plates or between stabilized and unstabilized films (Fig. 11).

The critical molar mass $\mathrm{M}_{\mathrm{c}}$ appears thus as a useful embrittlement criterion, at least in a first approach. Hydrolysis studies lead to similar observations with close $\mathrm{M}_{\mathrm{c}}{ }_{\mathrm{c}}$ values [24], suggesting that this critical molar mass value is an intrinsic property of PA11.

By assuming that $\mathrm{M}^{\prime} \mathrm{C}$ is linked to the entanglement network into amorphous phase by the relationship $\mathrm{M}^{\prime} \mathrm{C} \sim 5 \mathrm{M}_{\mathrm{e}}$, we can deduce that the molar mass between entanglement $\left(\mathrm{M}_{\mathrm{e}}\right)$ is close to $2 \mathrm{~kg} \mathrm{~mol}^{-1}$. Unfortunately literature data on entanglement molar mass on PA11 determined from rheometric measurements are inexistent to our knowledge. We can only notice that the $\mathrm{M}_{\mathrm{e}}$ above value is close to $M_{e}$ values for PA66 proposed in literature [see for instance [25]]. The ductile-brittle transition is explained as follows: ductility is linked to chain drawing and this latter is only possible if the chains participate to a network. Chain scissions lead to the progressive destruction of the entanglement network; when the molar mass reaches about 5 times the entanglement molar mass, disentanglement by chain slipping becomes easy in the timescale of tensile testing and cracks can propagate very easily because the only forces they have to overcome are Van der Waals ones.

The reality of a relatively sharp ductile-brittle transition and its relationship with entanglement molar mass is well established in the case of glassy polymers [9]. This transition can be also observed in semi-crystalline polymers having its amorphous phase in rubber state, as polyethylene, polyoxymethylene or polypropylene [3] but in this case, it has been shown that the ratio $\mathrm{M}_{\mathrm{c}} / \mathrm{M}_{\mathrm{e}}$ is considerably higher than 5 and that the true critical structural parameter is the interlamellar distance, this latter being more or less sharply linked to molar mass. Does PA11 belong to this latter family of polymers or to the family of amorphous polymers? It seemed to us interesting to try to answer this question which requires a specific study of tensile testing at temperatures higher than $\mathrm{T}_{\mathrm{g}}$.

\subsection{Tensile testing temperature influence on $M^{\prime}{ }_{C}$}

If the previous section was dedicated to the assessment of $\mathrm{M}^{\prime} \mathrm{C}$ at $\mathrm{RT}$, the effect of the tensile test temperature on $\mathrm{M}^{\prime} \mathrm{C}$ below and

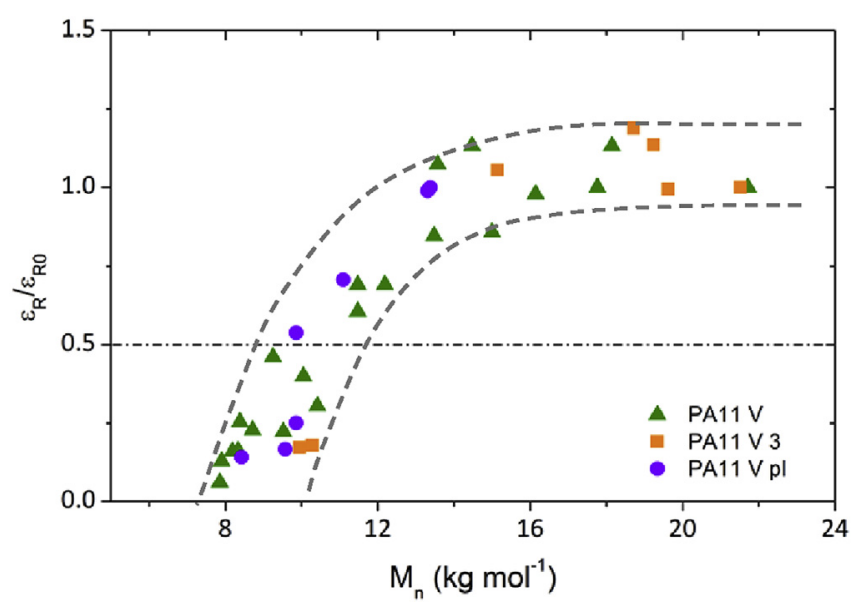

Fig. 11. Normalized strain at failure (@ RT) as a function of molar mass $\left(M_{n}\right)$ for PA11 with and without stabilizer and $70 \mu \mathrm{m}$ and $1 \mathrm{~mm}$ thick samples. 
above $T_{g}\left(\sim 60^{\circ} \mathrm{C}\right)$ is here examined. In $\S 3.3$, we have followed the embrittlement process at $50{ }^{\circ} \mathrm{C}, 80^{\circ} \mathrm{C}$ and $110{ }^{\circ} \mathrm{C}$ tensile testing temperature. Since embrittlement occurs at all these temperatures as at $25^{\circ} \mathrm{C}$, it is possible to determine the critical value $\mathrm{M}^{\prime}{ }_{\mathrm{C}}$ for each temperature. As a result, it is now possible to plot $\mathrm{M}_{\mathrm{C}}^{\prime}$ as a function of the testing temperatures in Fig. 12 for PA11 V samples.

It appears that $\mathrm{M}^{\prime} \mathrm{C}$ decreases linearly with temperature from $11 \mathrm{~kg} \mathrm{~mol}^{-1}$ at $25^{\circ} \mathrm{C}$ to $8 \mathrm{~kg} \mathrm{~mol}^{-1}$ at $110^{\circ} \mathrm{C}$. Surprisingly, no significant discontinuity is observed at $\mathrm{T}_{\mathrm{g}}$, that could be attributed to the fact that the glass transition is relatively wide compared to the temperature range. Since it well established that the ductile-brittle transition results from the competition between plastic deformation (shear mode) and brittle behavior linked to cavitation damage [26], the ductile-brittle transition is then expected to shift towards lower molar mass when temperature increases because plastic deformation is preferentially promoted.

\subsection{Influence of modification of crystalline morphology on the ductile-brittle transition}

We have seen that the ductile-brittle transition in the molar mass scale (Fig. 9) extends between 9 up to $11 \mathrm{~kg} \mathrm{~mol}^{-1}$ for PA11 films at $\mathrm{T}=25{ }^{\circ} \mathrm{C}$. This extent can be presumably attributed to crystallinity changes occurring during degradation since a brittle behavior can be promoted by increasing crystallinity for a given molar mass [27]. To put in evidence the influence of crystallinity on the ductile-brittle transition, we have plotted in a first approach the crystallinity ratio as a function of molar mass for all PA11 films during degradation (Fig. 13) and indicated if the mechanical behavior is brittle $\left(\varepsilon_{R} / \varepsilon_{R 0}<0.5\right)$ or ductile $\left(\varepsilon_{R} / \varepsilon_{R 0}>0.5\right)$.

On the $\mathrm{X}_{\mathrm{C}}-\mathrm{M}_{\mathrm{n}}$ map shown in Fig. 13, the open symbols correspond to samples having a brittle behavior whereas the filled symbols correspond to samples having a ductile behavior. As a result, the $X_{C}-M_{n}$ map exhibits a relatively clear frontier between ductile and brittle behavior: it is noteworthy that this frontier does not only depend on $\mathrm{M}_{\mathrm{C}}{ }_{\mathrm{C}}$ (which should correspond to a vertical frontier) but also slightly on $\mathrm{X}_{\mathrm{C}}$. In other words, a PA11 sample having a molar mass equal to $11 \mathrm{~kg} \mathrm{~mol}^{-1}$ can be considered as ductile if $\mathrm{X}_{C}$ is lower than 0.25 and brittle if $\mathrm{X}_{C}$ is higher than 0.25 . As a conclusion, if the only knowledge of molar mass drop could be sufficient to predict the ductile-brittle transition in a coarse grained approach, crystalline fraction is also required to predict carefully the transition knowing that crystallinity increase leads to promote brittle behavior.

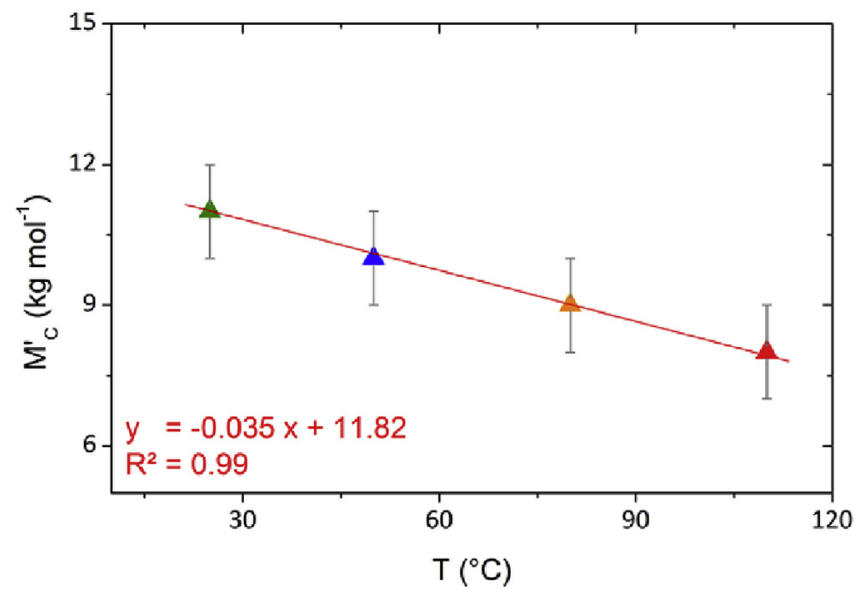

Fig. 12. Critical molar mass as a function of tensile testing temperature $(25,50,80$ and $\left.110^{\circ} \mathrm{C}\right)$.

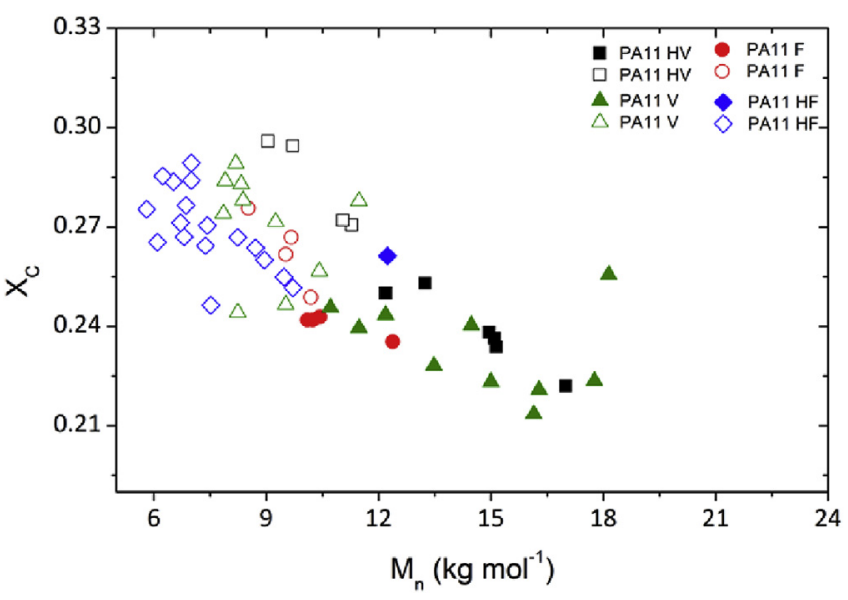

Fig. 13. Crystallinity ratio as a function of molar mass: open symbols are associated to a brittle behavior and full symbols to a ductile behavior.

However, the crystallinity ratio depends on the thermal story and cannot be an accurate criterion for degradation induced embrittlement. In contrast, the interlamellar distance $l_{\mathrm{a}}$ has been proven to be a suitable criterion for polyethylene [3] where the critical value was $l_{\mathrm{ac}} \sim 6 \mathrm{~nm}$. Using $\mathrm{l}_{\mathrm{a}}$ values for PA11 plates shown in Fig. 5 and strain at break values shown in Fig. 7, we have plotted the relative strain at break as a function of interlamellar distance in Fig. 14.

The resulting curve displays an inflection point near to $\mathrm{l}_{\mathrm{a}}=6.5 \mathrm{~nm}$. Indeed, the closeness of this value with PE one could result from a coincidence; however it is tempting to consider this curve as the key representation of the embrittlement mechanism and that the interlamellar distance of about $6 \mathrm{~nm}$ could correspond to micromechanical conditions almost independent of the polymer structure, at least for such flexible chains.

According to recent simulation methods to model tie chains and trapped entanglements in semi-crystalline polymers $[28,29]$, tie chain fraction for our $l_{c} / l_{a}$ value at ductile brittle transition $\left(l_{c} \mid\right.$ $\left.l_{a} \sim 0.25\right)$ is quite low $(<5 \%)$. Since the chain scission number is below $0.05 \mathrm{moL} \mathrm{kg}{ }^{-1}$ when ductile-brittle transition occurs (PA11V), the probability to cut a tie is very low. As a result, although an increase crystalline morphology promotes a brittle behavior (by modifying the stress-strain state into the amorphous region for instance), the key factor governing the

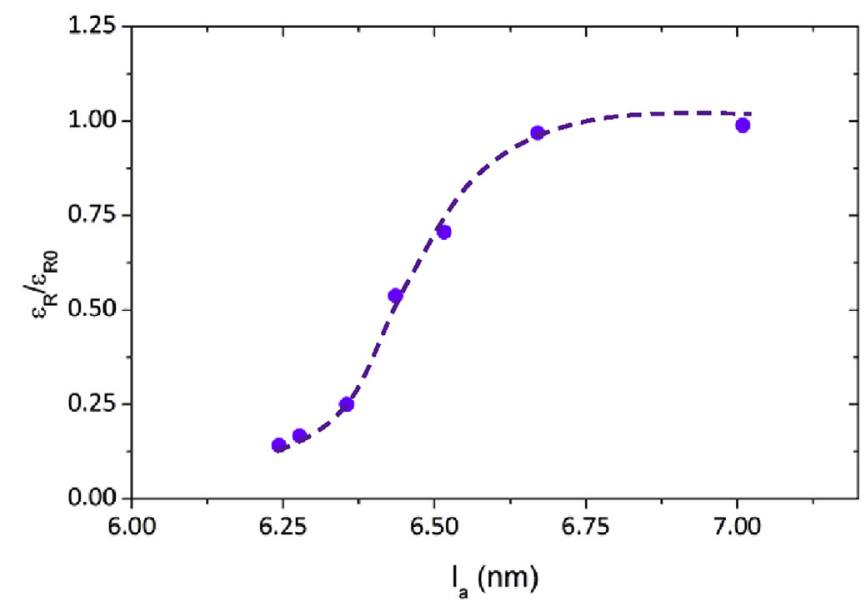

Fig. 14. Normalized strain at failure (@ $25^{\circ} \mathrm{C}$ ) as a function of amorphous layer thickness for $1 \mathrm{~mm}$ thick PA11 samples. 
ductile-brittle transition is associated to the entanglement network mechanical properties.

We have previously distinguished two families of linear polymers differing by the causal chain of embrittlement:

For family A (most amorphous polymers):

Chain scission $\rightarrow$ decrease of molar mass $\rightarrow$ destruction of the entanglement network $\rightarrow \quad$ easy disentanglement $\rightarrow$ embrittlement.

For Family B (certain semi-crystalline polymers having their amorphous phase in rubbery state):

Chain scission $\rightarrow$ decrease of molar mass $\rightarrow$ chemicrystallization $\rightarrow$ decrease of interlamellar distance $\rightarrow$ embrittlement.

Until now, both families were distinguished by the value of the critical molar mass ratio $\mathrm{M}^{\prime}{ }_{c} / \mathrm{M}_{\mathrm{e}}$ close to 5 for family A and 50 for family B. In the case of PA11, this ratio is close to 5 so that it could belong to family A, but it displays a critical interlamellar distance of about $6 \mathrm{~nm}$ as polymers of family B. It will be necessary to include other polymers in the comparison to determine which parameter $\left(\mathrm{M}^{\prime}{ }_{\mathrm{c}} / \mathrm{M}_{\mathrm{e}}=50\right.$ or $\left.\mathrm{l}_{\mathrm{ac}} \sim 6 \mathrm{~nm}\right)$ lacks of universality.

\section{Conclusions}

The embrittlement of PA11 when this latter is submitted to thermal oxidation was investigated in depth in order to establish relationships between chemical changes and tensile properties, the final objective being to build a predictive modelling for polyamide service life. It was shown that oxidative degradation is responsible for strain at break drop whereas yield properties $\left(\sigma_{\mathrm{y}}\right)$ remain almost unchanged. Concerning the influence of the tensile testing temperature, it has been pointed out that an increase of temperature leads to delays the embrittlement process, in other words the strain at break drop occurs for higher oxidation conversion degree.

Since it is well known that amorphous polymers become brittle when their molar mass becomes lower than a critical value $\left(\mathrm{M}^{\prime} \mathrm{C}\right)$, we have tested several PA11 samples differing by their initial molar mass, stabilizers content and thickness to assess a critical molar value. It appears that all PA11 samples become brittle when $M_{n}$ is below about $10 \mathrm{~kg} \mathrm{~mol}^{-1}$. The fact that all PA11 samples display about the same $\mathrm{M}_{C}{ }_{C}$ value seems to indicate that $\mathrm{M}_{C}^{\prime}$ is the property governing the ductile-brittle transition for a given tensile test temperature. Furthermore, we have shown the $\mathrm{M}^{\prime} \mathrm{C}$ decreases with this tensile test temperature, this latter promoting plastic deformation over brittle behavior.

In the literature, $\mathrm{M}^{\prime} \mathrm{C}$ is often interpreted as a characteristic of the entanglement network. This latter is mechanically active provided that molar mass is more than five times higher than the molar mass between entanglements $\left(\mathrm{M}_{\mathrm{e}}\right)$. If this approach seems to be consistent with our results $\left(\mathrm{M}^{\prime}{ }_{\mathrm{C}}(\mathrm{PA} 11) \sim 5 \mathrm{M}_{\mathrm{e}}\right.$ (PA11), we cannot set out the hypothesis that the degradation induced crystallinity increase (chemi-crystallization) could also be involved. Indeed, since the interlamellar thickness $\left(l_{\mathrm{a}}\right)$ is intimately associated to molar mass through a scaling law, it appears that embrittlement occurs when $l_{a}$ reaches a value of $6.5 \mathrm{~nm}$. According to this approach, the thickness of the interlamellar layer would be a crucial factor in determining precisely whether a sample is brittle or ductile.

\section{Acknowledgments}

Many thanks are addressed to ARKEMA's experts for their valuable assistance in bringing out this article: Florence Churlaud, Christophe Degoulet and Frédérique Pery. We would also like to extend our gratitude to Vincent Michel for his involvement in XRD measurements and Karl Potier for mechanical tests.

\section{References}

[1] R. Li, X. Hu, Study on discoloration mechanism of polyamide 6 during thermos-oxydative degradation, Polym. Degrad. Stab. 62 (3) (1998) 523-528.

[2] W. Dong, P. Gisjman, Influence of temperature on the thermos-oxidative degradation of polyamide 6 films, Polym. Degrad. Stab. 95 (6) (2010) 1054-1062.

[3] B. Fayolle, L. Audouin, J. Verdu, A critical molar mass seperating the ductile and brittle regimes as revealed by the thermal oxidation in polypropylene, Polymer 45 (12) (2004) 4323-4330.

[4] W.L. Hawkins, W. Matreyek, F.H. Winlows, The morphology of semicrystalline Part I. The effect of temperature on the oxidation of polyolefins, J. Polym. Sci. 41 (138) (1959) 1-11.

[5] J.B. Knight, P.D. Calvert, N.C. Billingham, Localization of oxidation in poly propylene, Polymer 26 (11) (1985) 1713-1718.

[6] M. Koutny, J. Lemaire, A.M. Delort, Biodegradation of polyethylene films with prooxidant additives, Chemosphere 64 (2006) 1243-1252.

[7] O. Okamba-Diogo, E. Richaud, J. Verdu, F. Fernagut, J. Guilment, B. Fayolle Molecular and macromolecular changes in polyamide 11 during therma oxidation, Polym. Degrad. Stab. 109 (2014) 123-132.

[8] B. Fayolle, E. Richaud, X. Colin, J. Verdu, Review: degradation-induced embrittlement in semi-crystalline polymers having their amorphous in rubbery state, J. Mater. Sci. 43 (22) (2008) 6999-7012.

[9] Y. Sha, C.Y. Hui, A. Ruina, E.J. Kramer, Continuum and discrete modeling of craze failure at a crack tip in a glassy polymer, Macromolecules 28 (7) (1995 2450-2459.

[10] C. Creton, E.J. Kramer, H.R. Brown, C.Y. Hui, Adhesion and fracture of interfaces between immiscible polymers: from molecular to the continuum scale, Adv. Polym. Sci. 156 (2001) 53-136.

[11] A. Peterlin, Plastic deformation of crystalline polymers, J. Mater. Sci. 6 (6) (1971) 490-508.

[12] J. Rault, Robelin Souffache, Long periods in slow-cooled linear and branched PE, J. Polym. Sci. Part B 27 (6) (1989) 1349-1373.

[13] G. Papet, L. Jirackova-Audouin, J. Verdu, Diffusion controlled radiochemica oxidation of low density polyethylene-I. Depth dependence of morphological changes, Radiat. Phys. Chem. 29 (1) (1987) 65-69.

[14] B. Fayolle, J. Verdu, Radiation aging and chemi-crystallization processes in polyoxymethylene, Eur. Polym. J. 47 (11) (2011) 2145-2151.

[15] B. Fayolle, J. Verdu, D. Piccoz, A. Dahoun, J.M. Hiver, C. G'Sell, Thermooxidative aging of polyoxymethylene. Part 2: Embrittlement mechanisms, J. Appl Polym. Sci. 111 (2009) 469-475.

[16] M.S. Rabello, J.R. White, Crystallization and melting behavior of photodegraded polypropylene - I. Chemi-crystallization, Polymer 38 (1997) 6379-6387.

[17] G. Ahlblad, D. Forsström, B. Stenberg, B. Terselius, T. Reitberger, L. G. Svensson, Oxidation profiles of polyamide 6,6 studied by imaging chemiluminescence and FTIR, Polym. Degrad. Stab. 55 (1997) 287-293.

[18] O. Okamba-Diogo, E. Richaud, J. Verdu, F. Fernagut, J. Guilment, B. Fayolle, Molecular and macromolecular structure changes in polyamide 11 during thermal oxidation - kinetic modeling, Polym. Degrad. Stab. 120 (2015 $76-87$.

[19] M. Inoue, Studies on crystallization of high polymers by differential thermal analysis, J. Polym. Sci. Part A Gen. Pap. 1 (8) (1963) 2697-2709.

[20] Hammersley AP Scientific software FIT2D.

[21] I. Narisawa, M. Ishikawa, Crazing in semicrystalline polymers, Adv. Polym. Sci. 91/92 (1990) 353-391.

[22] fourth ed. third ed.D.W. Van Krevelen, K. Te Nijenhuis (Eds.), Properties of Polymers, Elsevier, Amterdam, 2009.

[23] X.C. Zhang, M.F. Butler, R.E. Cameron, The ductile-brittle transition of irradiated isotactic polypropylene studied using simultaneous small angle X-ray scattering and tensile deformation, Polymer 41 (2000) 3797-3807.

[24] G. Serpe, N. Chaupart, J. Verdu, Ageing of polyarnide 11 in acid solutions Polymer 38 (1997) 1911-1917.

[25] S. Wu, Chain structure and entanglement, J. Polym. Sci. Part B Polym. Phys. 27 (1989) 723-741.

[26] C.J.G. Plummer, Micromechanical deformation mechanisms in polyolefins, in G.H. Michler, F.J. Balta-Calleja (Eds.), Mechanical Properties of Polymers Based on Nanostructure and Morphology, Taylor and Francis, 2005, pp. 215-244. Chap. 6.

[27] I.G. Voigt-Martin, L. Mandelkern, A quantitative electron microscopic study of the crystallite structure of molecular weight fractions of linear polyethylene, J. Polym. Sci. Part B 22 (1984) 1901-1917.

[28] F. Nilsson, X. Lan, T. Gkourmpis, M.S. Hedenqvist, U.W. Gedde, Modelling tie chains and trapped entanglement in polyethylene, Polymer 53 (2012) 3594-3601.

[29] A. Moyassari, S.H. Mostafavi, T. Gkourmpis, M.S. Hedenqvist, U.W. Gedde, Nilsson F simulation of semicrystalline polyethylene: effects of short-chain branching on tie chains and trapped entanglements, Polymer 72 (2015) 177-184. 